\title{
Autosomal dominant intermediate Charcot-Marie-Tooth disease type A
}

INSERM

\section{Source}

INSERM. (1999). Orphanet: an online rare disease and orphan drug data base. Autosomal dominant intermediate Charcot-Marie-Tooth disease type A. ORPHA:100043

Autosomal dominant intermediate Charcot-Marie-Tooth disease type $\mathrm{A}$ is a rare hereditary motor and sensory neuropathy characterized by intermediate motor median nerve conduction velocities (usually between 25 and $45 \mathrm{~m} / \mathrm{s}$ ) and signs of both demyelination and axonal degeneration in nerve biopsies. It presents with usual clinical features of Charcot-Marie-T ooth disease (progressive muscle weakness and atrophy of the distal extremities, distal sensory loss, reduced or absent deep tendon reflexes, and feet deformities) in the first to second decade of life with steady progression until the fourth decade, severe progression and stabilization afterwards. 